\title{
Profile of Pediatric Patients with Cerebral Palsy at the Department of Rehabilitation Medicine, Philippine General Hospital
}

\author{
Angelita Roma P. Hebreo, ${ }^{1}$ Cynthia D. Ang-Muñoz, ${ }^{2}$ Joycie Eulah E. Abiera, ${ }^{2}$ \\ Monalisa L. Dungca and Betty D. Mancao ${ }^{2}$ \\ ${ }^{1}$ Department of Rehabilitation Medicine, Philippine General Hospital, University of the Philippines Manila \\ 2Department of Rehabilitation Medicine, College of Medicine and Philippine General Hospital, University of the Philippines Manila
}

\begin{abstract}
Objectives: Data is necessary for a hospital-wide cerebral palsy (CP) profile, this being the leading pediatric diagnosis at the PGH Rehabilitation Medicine Out Patient clinic. This study aims to identify clinical features, severity of disability and common interventions in pediatric CP patients.
\end{abstract}

Methods: CP profile data collection forms were accomplished from September 2014 to December 2015.

Primary Results: Among 125 participants: 55\% were < 5 years old, $47 \%$ were delivered vaginally, $42 \%$ had perinatal onset of condition, 34\% had normal birth weight and 23\% were moderately preterm. Most were quadriplegic (36\%) and spastic (50\%). Primary caregivers were mostly mothers (45\%) and $<20$ years old (38\%). Mobility-wise, $29 \%$ had Gross Motor Function Classification System score of 3. For hand function, 31\% scored 2 in the Manual Ability Classification System and $26 \%$ were 'below average' in the Peabody Developmental Motor Skills-2. Common problems were: feeding (100\%), communication (63\%), seizure (58\%), visual (56\%) and auditory (54\%). Majority (73\%) had access to government medical facilities; $18 \%$ had no access. Physical (64\%) and occupational (29\%) therapy were common interventions; $29 \%$ received special education.

Conclusion: A hospital-wide cerebral palsy profile should be established to monitor CP, given its multifactorial cause and complex functional impact. Trends should be correlated with maternal and patient factors, healthcare provision and socioeconomics.

Key Words: Cerebral palsy registry, cerebral palsy, rehabilitation

\section{Introduction}

Cerebral palsy (CP) encompasses a group of permanent, non-progressive disorders of the developing brain, affecting posture, movement, and motor coordination caused by damage to one or more specific areas of the brain, usually

\footnotetext{
Corresponding author: Angelita Roma P. Hebreo, MD

Department of Rehabilitation Medicine

Philippine General Hospital

University of the Philippines Manila

Taft Avenue, Ermita, Manila 1000 Philippines

Telephone: +6309176224336

Email: aphebreo@up.edu.ph
}

occurring during fetal development; before, during or shortly after birth; during infancy; or during early childhood. ${ }^{1}$ Often, there may be associated deficits in cognition, sensation, communication, and behavior; seizure disorder; and secondary musculoskeletal complications such as contractures as defined by Rosenbaum and colleagues. ${ }^{1}$

Cerebral palsy has been recognized as the most common motor disability during childhood by the Center for Disease Control (CDC), with prevalence estimates of 1.5 to $>4$ per 1,000 live births based on population-based studies worldwide. ${ }^{2}$ In the US, it has been estimated that 1 in 278 infants born every year will be diagnosed as CP with a projected total of 764,000 children and adults manifesting one or more of the symptoms of this disorder. ${ }^{3}$ The Surveillance of Cerebral Palsy in Europe (SCPE) in 2002 stated that the incidence of $\mathrm{CP}$ in Europe is 2 per 1,000 children. ${ }^{4}$ Cans et al in 2004 cited the impact of this condition, constituting $67 \%$ of severe motor disabilities in childhood. ${ }^{4}$ The situation in the local setting is no different from these statistical figures.

In a comprehensive status report of the Pediatric Rehabilitation Service of the Department of Rehabilitation Medicine, Philippine General Hospital in 2010, cerebral palsy is the leading diagnosis of new patients referred to the service on out-patient basis, totaling 329 out of 1,173 (28\%). ${ }^{5}$ The Department's 1996-1999 status report showed that among pediatric in-patient referrals, CP ranked third in the 1998 and 1999 patient census, and is consistently among the top five cases. ${ }^{6}$ Furthermore, based on the data of the Philippine Cerebral Palsy Incorporated, patients with CP outnumbered those with polio, spinal lesions, and other movement disorders combined, approximating 1 to $2 \%$ of the total population. ${ }^{7}$

Recognition of the use of registries as a resource for use in research is one of the biggest leaps in the field of medical research. Uldall and colleagues ascertained that most researches in $\mathrm{CP}$ are grounded on $\mathrm{CP}$ registries. A number of these registries have been published since the mid-1950s (Sweden in 1954) to early 1960s (England and Ireland in 1966), and increasing in number to include regional collaborative studies at present. Countries that have existing $\mathrm{CP}$ registries include: Sweden, United Kingdom, Ireland, Denmark, Australia, and recently the 
United States, as reported by Uldall and colleagues in 2001 and Cans et al in 2004. In 2006, the Cerebral Palsy Research Registry, a secure and expandable online database of cerebral palsy cases initiated at the Northwestern University in Chicago, USA, was published by Hurley and colleagues in $2011 .^{3}$

\section{Review of literature}

In Asia, a single CP registry exists in Japan and was published by Uldall and colleagues in 2001. ${ }^{8}$ A three-part study by Suzuki et al in 2009 was conducted in the Shiga Prefecture from year 1977 to 2000 that described cerebral palsy in terms of: 1) incidence pattern according to birth weight and age of gestation, ${ }^{9}$ 2) etiologies and risk factors, ${ }^{10}$ and 3) clinical features including the type, severity of disability, and complications. ${ }^{11}$ A 2006 prevalence study of $\mathrm{CP}$ in children aged six to 12 years old in Hong Kong showed an over-all prevalence of 1.3 per $1000 . .^{12}$ The authors of this study concluded that a CP registry could assist in monitoring the local prevalence of this condition. A recent 2013 Pakistan study on the prevalence of early childhood disability revealed that 5.5 in 1000 children under two years old and 6.4 in 1000 children two to five years of age have a disability, with $\mathrm{CP}$ as the most commonly recognized. ${ }^{13}$

Locally, the National Statistics Office census of population and housing conducted in 2010 reported that 16 in 1000 had a disability and $18.9 \%$ of these were children 0 to 14 years old. ${ }^{14}$ Philippine epidemiologic data on $\mathrm{CP}$ is limited to hospital or clinic censuses. Hand-searched data from several institutions catering to pediatric patients such as Philippine Children's Medical Center (PCMC), National Children's Hospital (NCH), and Philippine Cerebral Palsy Inc. (PCPI) showed that only censuses and patient lists existed; no registry with extensive data was available. Data from the Philippine General Hospital (PGH) Rehabilitation Medicine Out-Patient Department (OPD) showed that among 1,387 pediatric patients seen in 2012, 21.7\% were diagnosed with CP. ${ }^{15}$ A study conducted in 2009 reviewing a five-year referral history to the Section of Developmental Pediatrics, Department of Pediatrics of the Philippine General Hospital stated that $\mathrm{CP}$ is among the three most commonly referred conditions to the Section. ${ }^{16}$ De Leon and colleagues analyzed 1,950 patients with CP who registered at Elk's Cerebral Palsy Clinic from 1957 to 1963 as to prevalence, demographics, cause/onset of $\mathrm{CP}$, manner of delivery, and type of CP. ${ }^{17}$ However, the study did not include details on impairments, activity limitations, participation restriction, and rehabilitation treatment received. To date, there is no published extensive local epidemiologic study on this population, nor a published local CP registry as to the clinical features, and severity of disability of patients in this country. While the PGH Department of Rehabilitation Medicine had compiled status reports on the pediatric rehabilitation clinic and service since
1994, none of these included any comprehensive profile or registry of patients with cerebral palsy. Thus, there is a pressing need to create a profile of patients with $\mathrm{CP}$ as a preliminary framework for a registry, describing their needs and their families' concerns, with the goal of providing quality care in a more focused direction in the light of limited resources available in a tertiary government hospital.

The decline in neonatal mortality in the last two decades of the previous millennium led to an increase in the number of surviving infants at risk for developing cerebral palsy. ${ }^{8}$ Over the last decade, data showed that among adults with cerebral palsy without intellectual disability, 60 to $80 \%$ completed high school, 14 to $25 \%$ completed college, 25 to $55 \%$ were competitively employed, up to $61 \%$ were living independently in the community, and 14 to $28 \%$ were involved in long term relationships with partners or had established families. ${ }^{18}$ Therefore, regular monitoring of these patients is indispensable to promote positive functional outcomes. This may be accomplished through a registry.

Registries contain valuable information that can be used to: 1) monitor trends in the number, rate, and characteristics of children with $\mathrm{CP}, 2$ ) permit quick identification of subgroups for research, 3) assess function and quality of life, 4) evaluate cost of care or burden of disease, and 5) provide a venue for sharing expertise and practice to bring about costand time-efficient studies. To date, numerous studies have been conducted and there are more ongoing researches with the aid of these registries. ${ }^{19}$ It is therefore high time that a preliminary study be implemented to initiate a framework for a hospital-wide cerebral palsy profile. Using the World Health Organization (WHO) International Classification of Function, Disability, and Health; ${ }^{20}$ functional outcome measures such as the Gross Motor Function Classification System (GMFCS), ${ }^{21}$ Manual Ability Classification System (MACS), ${ }^{22}$ Functional Mobility Scale (FMS), ${ }^{23}$ and Peabody Developmental Motor Scale-2 Fine Motor Subscale (PDMS2), ${ }^{24}$ international guidelines from the 2009 World Cerebral Palsy Register Congress Survey Report; and the Cerebral Palsy Research Registry of Northwestern University in Chicago, significant key information were consolidated in a specially designed cerebral palsy data collection form for this study. The cerebral palsy data collection form that was used in this study was developed partly based on the Cerebral Palsy Research Registry of Northwestern University in Chicago with permission from the authors, ${ }^{3}$ with some modifications to improve the applicability in the local setting.

\section{Conceptual framework}

The framework for this study is presented in Figure 1. This is based on the World Health Organization (WHO) International Classification of Functioning, Disability and Health (ICF), which illustrates the interaction and integration of health conditions, individual factors, social factors, and contextual factors. 


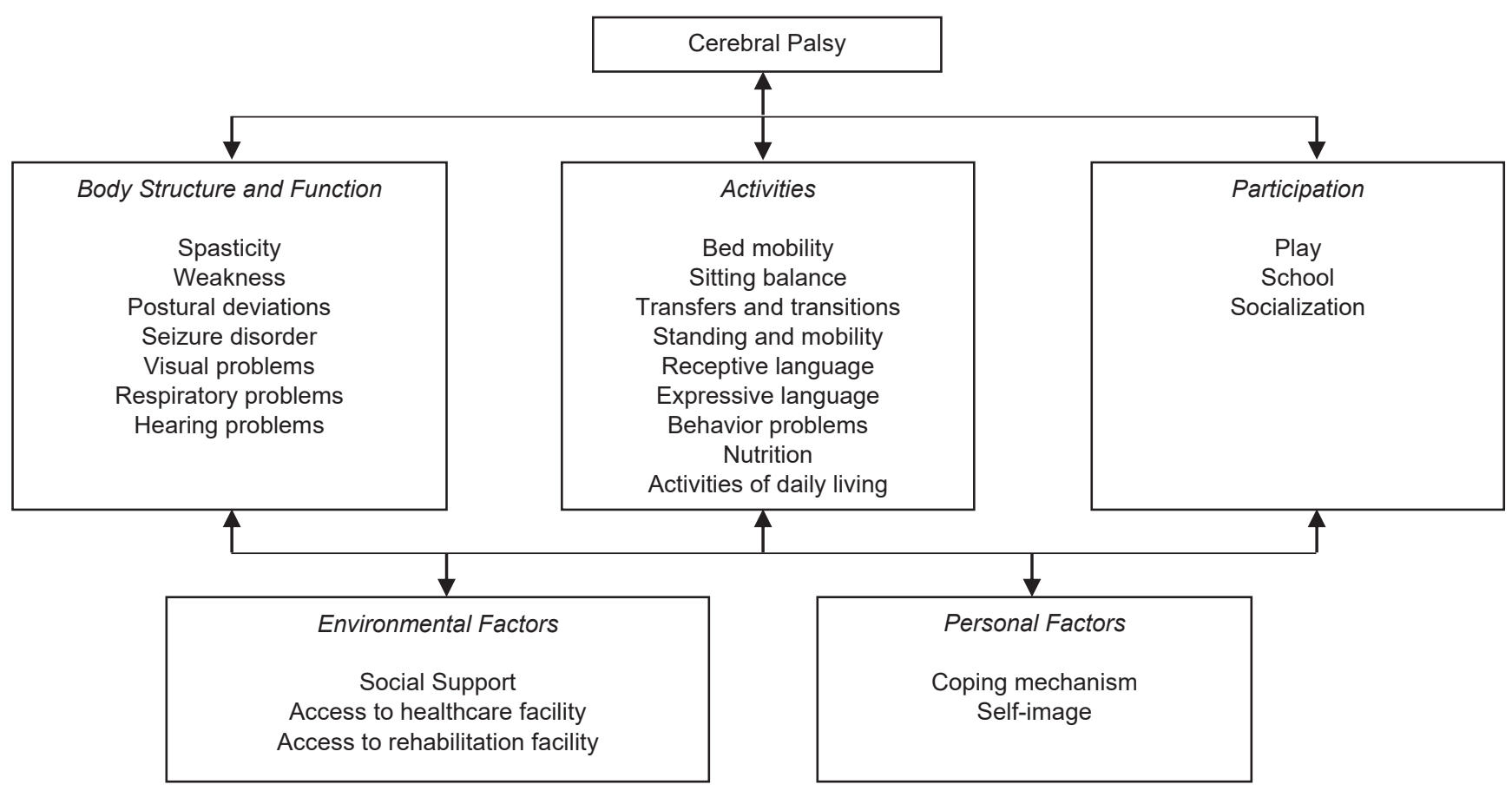

Figure 1. Conceptual framework describing the interaction among the various factors in patients with cerebral palsy, based on the WHO International Classification of Function.

Factors illustrated in this figure play a vital role in influencing the functional outcome in a child with cerebral palsy. With more alterations in body function and structure, such as spasticity and seizure disorder, more restrictions in activities and in participation would be anticipated in the patient. The European SPARCLE (Study of PARticipation of Children with cerebral palsy Living in Europe) project published in 2013 reported that adolescents with cerebral palsy "spent less time with friends and had less autonomy in their daily life than adolescents in the general populations." 25 They also have less participation in sports, with severity of motor and intellectual impairment bearing remarkable effect on frequency of participation. ${ }^{25}$ In addition, provision of management or intervention may be positively or negatively influenced by environmental factors and personal factors.

Family and social support, access to healthcare facility, and financial status will influence how a patient with $\mathrm{CP}$ would be managed through rehabilitation. Michelsen et al reported that identification of personal and environmental predictors of participation of adolescents with cerebral palsy is indispensable in order to design interventions directed to such predictors. ${ }^{26}$

\section{Objectives}

General objective

The main objective of the study was to determine the demographic, clinical features, severity of disability, and extent of rehabilitation interventions of pediatric patients with cerebral palsy from birth to $<19$ years old.
Specific objectives

The specific objectives were:

1) To determine the demographics of patients with $\mathrm{CP}$

2) To identify the causes of $\mathrm{CP}$

3) To describe the clinical features of children with $\mathrm{CP}$ in terms of: a) patient characteristics, b) maternal history, c) pregnancy and neonatal history, d) diagnostic information, e) medical conditions, and f) medical and/or surgical intervention

4) To determine the severity of disability of children with $\mathrm{CP}$ according to:

a. Alteration in structure and function as measured by limb involvement, tone abnormalities, sensorium and orientation, seizure, nutritional problems, impairments in vision, impairments in hearing, and respiratory problems

b. Limitation in activity as measured by sitting ability, need for assistive device, communication problems, behavioral problems, feeding problems, Gross Motor Function Classification System (GMFCS), Manual Ability Classification System (MACS), Functional Mobility Scale (FMS), and Peabody Developmental Motor Scale Fine Motor Subscale (PDMS-2)

c. Restriction in participation as measured by schooling, access to healthcare, access to rehabilitation, and family income

5) To determine extent of rehabilitation intervention provided to children with $\mathrm{CP}$ 


\section{Methods}

Study design

This study utilized a cross sectional study design.

\section{Participants}

The participants were patients diagnosed with cerebral palsy from birth to $<19$ years old who consulted at the PGH Rehabilitation Medicine Out-Patient Department from September 1, 2014 to December 31, 2015.

\section{Inclusion criteria}

All of the following criteria were fulfilled for inclusion in the study: 1) must have a disorder of movement or posture, 2) must have a loss of motor function, 3) condition must be non-progressive, 4) condition must be permanent, but not unchanging, 5) must be from birth to < 19 years old, and 6) with or without cranial imaging studies (eg, computed tomography scan, magnetic resonance imaging, ultrasound, and others).

\section{Exclusion criteria}

A patient was excluded if any of the following was present: 1) any motor impairment that is self-limiting, 2) degenerative or progressive central nervous system (CNS) or musculoskeletal disorders, 3) condition was acquired beyond 5 years of age (6 out of 25 registries included in the Survey Report of the World Cerebral Palsy Register Congress 2009 used 5 years old as their maximum age at which the post-neonatal brain damage could be acquired), ${ }^{20}$ and 4) condition was hereditary.

\section{Study site}

The study was conducted at the PGH Rehabilitation Medicine OPD. This was the site for patient recruitment, history taking, and physical examination of eligible participants, and assessment of mobility and hand function. A separate evaluation on hand function of children less than four years old using the Peabody Developmental Motor Scale-2 Fine Motor Subscale (PDMS-2) was administered by an occupational therapist on the same day at the Occupational Therapy Section of the Department at the main hospital.

\section{Study duration}

Recruitment period was from September 1, 2014 to December 31, 2015.

\section{Sample size}

The study utilized purposive sampling among children with CP. The participants were selected from patients who consulted at the PGH Rehabilitation Medicine OPD who satisfied the inclusion criteria during the study period.
Study procedure

Announcements in the form of flyers regarding the study were posted on the bulletin boards at the hospital's OPD, hospital lobby, two pediatric wards, and Rehabilitation Medicine Ward and outpatient clinic a few weeks prior to the conduct of the study to inform potential participants and physicians regarding recruitment and participation to the study. Pilot testing of the $\mathrm{CP}$ data collection form was performed prior to recruitment and data collection. Once a patient satisfied the inclusion criteria, written informed consent was secured from the participant and parent or legal guardian using the Informed Consent Form (Appendix A) and the Assent Form for participants who are minors. A Cerebral Palsy (CP) Data Collection Form (Appendix B) was accomplished by the Department of Rehabilitation Medicine residents including the principal investigator (PI) at the OPD from September 1, 2014 to December 31, 2015. Assessment of each participant entailed: 1) interview of the mother or legal guardian and/or the patient if he or she is communicative, 2) physical examination of the patient, and 3) review of the patient's chart. Each evaluation took approximately 30 to 45 minutes. Snacks were provided for the participants. Should there be a need for urgent medical attention, the resident conducting the evaluation was to bring the participant to the hospital's emergency room for prompt care. Residents who collected the data were oriented by the PI on the use of the data collection form prior to the implementation of the study to ensure accuracy and completeness of data collection. A separate Peabody Developmental Motor Scale-2, Fine Motor Subscale (PDMS-2) evaluation was performed by an occupational therapist on the same day at the Occupational Therapy Section of PGH, with provision for re-scheduling depending on time constraints and participant's cooperation. Only the PI had access to the accomplished data collection forms.

The CP data collection form used in this study was developed partly based on the Cerebral Palsy Research Registry of Northwestern University in Chicago with permission of the authors. ${ }^{3}$ Some modifications were included to improve the applicability in the local setting. This tool included patient characteristics, maternal history, pregnancy and neonatal history, diagnostic information, medical and surgical information, rehabilitation intervention, alterations in structure and function, activity limitations, and social or participation restrictions. These key variables were further classified into the following: contact variables, medical variables, developmental variables, participation variables, and other variables (Table 1 ).

To determine the prevalence of patients with $\mathrm{CP}$ at the PGH Rehabilitation Medicine OPD, the percentage of cases of CP among the pediatric patients seen from September 1, 2014 to December 31, 2015 was calculated. Patient characteristics including age, sex, and ethnicity or race were also described. Data on the maternal history including 
Table 1. Key variables collected in the cerebral palsy registry

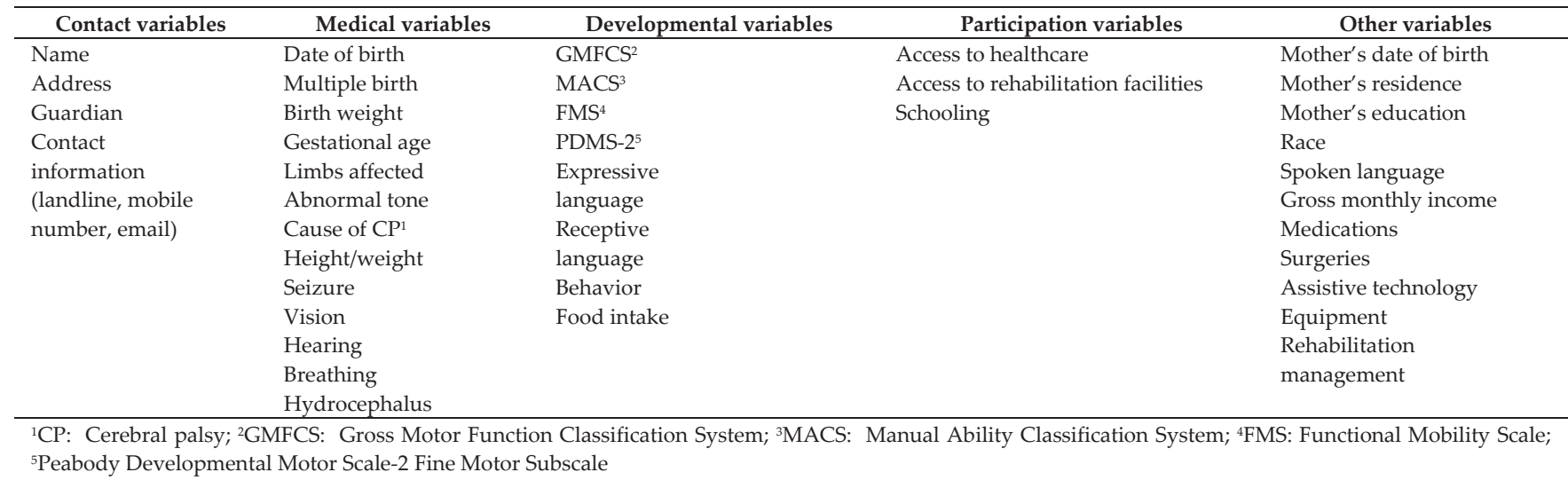

information on the primary caregiver, mother's age, mother's previous birth history, and parents' educational level, occupation, and primary language were recorded. To identify the causes of $\mathrm{CP}$, diagnostic information was described. These included age at diagnosis or onset, cause, and diagnostic tests or imaging examinations done. Pregnancy and neonatal history including age of gestation, birth weight, mode of delivery, and prenatal, perinatal or postnatal complications were gathered.

For the severity of $\mathrm{CP}$, alterations in structure and function, activity limitations, and participation restrictions were identified. Alteration in structures and function included limb involvement, tone abnormalities, sensorium and orientation, seizure, nutritional problems, impairment in vision and hearing, and respiratory problems. Activity limitations included sitting ability, ambulation and mobility issues, need for assistive device (wheelchair, stroller, walker, crutches, cane, upper extremity orthosis, lower extremity orthosis, spine orthosis, seating device, local walker), communication problems, behavioral problems, feeding issues, Gross Motor Function Classification System (GMFCS) score, Manual Ability Classification System (MACS) score, Functional Mobility Scale (FMS) score, and Fine Motor Subscale of Peabody Developmental Motor Scale-2 (PDMS-2) raw score. The MACS and FMS are tools used in evaluating children aged four years up to 18 years. The PDMS-2 Fine Motor Subscale was used to assess the hand function of patients less than four years in lieu of the MACS, and GMFCS in lieu of FMS for patients less than four years. Social or participation restrictions included problems with schooling, access to healthcare, access to rehabilitation facilities, and family gross monthly income.

Medical and surgical intervention including orthopedic surgery for the upper extremities, lower extremities, and spine; shunt insertion; tube feeding; and medications for seizure, spasticity and other conditions were identified. Subgroup analysis was performed to evaluate the relationship of spasticity to mobility (GMFCS score) and to hand function (MACS score and PDMS-2 score).
Statistical analysis

Data gathered were encoded using Microsoft Excel Version 2010 and analyzed using Epi Info Version 6. A coding manual was used for encoding data from the data collection form. Descriptive statistics was used. Demographic data were summarized using frequencies and percentages. The severity of disability was measured using ordinal scale (GMFCS score, MACS score, FMS score, and PDMS-2 Fine Motor Subscale raw score). The following characteristics of patients were measured using ordinal scale: limbs affected, seizure disorder, visual problems, respiratory problems, hearing problems, problems with expressive and receptive language, behavioral problems, nutritional status, and gross monthly family income. Continuous variables, eg, birth weight, gestational age by last menstrual period (LMP), and/or ultrasonography, were analyzed using interval scale. Nominal scale was used to assess the following categorical variables: onset and cause of cerebral palsy, limbs affected, tone abnormalities, medications, surgical procedures, assistive device use, and compliance and rehabilitation intervention. Subgroups analysis was performed to determine the relationship of GMFCS score, MACS score and PDMS-2 score with spasticity.

\section{Ethical consideration}

The protocol was submitted to the University of the Philippines Manila Research Ethics Board (UPMREB) for approval prior to study implementation. Participation in the study was voluntary. "Informed Consent Form" and "Assent Form" were signed by the parent or legal guardian and the patient, respectively. Refusal to take part did not, in any way, affect the services provided to the patients. Should the participant or the parent or legal guardian decide to withdraw from the study, he or she may do so at any time without affecting their rehabilitation management. Remuneration was not provided; however, snacks were given to the participants. Contact information of the principal investigator was made available to the participants and their parent or legal guardian for any question or 
concern that needed to be addressed during the study. All data gathered from the study were kept private and confidential, accessed only by the PI and supervising investigators (SIs). There was no conflict arising from financial, familial, or proprietary considerations of the PI, SIs, or the study site.

\section{Results}

The study included a total of 125 participants who were seen at the PGH Rehabilitation Medicine Out-Patient Department, from September 1, 2014 to December 31, 2015. This corresponded to approximately 8 patients seen per month.

Majority of the cerebral palsy patients seen were males, comprising approximately $58 \%$ of the total number of participants. All of them were of Asian race born in the Philippines. Filipino was the primary language spoken by majority of the caregivers (80\%), while the remaining $20 \%$ spoke both Filipino and English.

Majority of the primary caregivers of the participants $(45 \%)$ were mothers, most of whom were younger than 20 years old (38\%), had completed high school education (42\%), and were housewives/husbands who were not employed (72\%) (Table 2).

Table 2. Distribution of $\mathrm{CP}$ patients as to primary caregiver profile

\begin{tabular}{lcc}
\hline Characteristic & Frequency $\mathbf{( n = 1 2 5 )}$ & Percentage \\
\hline Primary caregiver & 56 & \\
Mother & 32 & 44.80 \\
Father & 17 & 25.60 \\
Sibling & 20 & 13.60 \\
Relative & & 16.00 \\
Mother's age (in years) & 47 & \\
$<20$ & 33 & 37.60 \\
$20-29$ & 29 & 26.40 \\
$30-39$ & 15 & 23.20 \\
$\geq 40$ & & 12.00 \\
Highest educational level & 32 & \\
Did not finish high school & 53 & 25.60 \\
High school graduate & 21 & 42.40 \\
Some college & 19 & 16.80 \\
College graduate & 0 & 15.20 \\
Graduate degree & & 0.00 \\
Caregiver occupation & 91 & 72.80 \\
Housewife/husband & 25 & 20.00 \\
Self-employed & 10 & 8.00 \\
Retired & & \\
\hline
\end{tabular}

Review of maternal history showed that mothers of the patients had a history of live birth (35\%) and miscarriage of unknown cause $(29 \%)$, while death in utero was noted in approximately $2 \%$. There were no multiple gestations nor stillbirths. The maternal history was unknown in $38 \%$. The informants, who were either siblings or relatives, did not have sufficient knowledge on this information.

Fifty-five percent of the patients were in the zero to four years age group, followed by five to nine years (25\%), 10 to 14 years $(14 \%)$, and 15 to 18 years (6\%). Majority were delivered vaginally $(47 \%)$, while the rest by caesarian section or data was unknown to the informant. The principal cause and onset of the condition was perinatal (42\%) (Table 3). Table 3 also shows that $34 \%$ had normal birth weight, while approximately $28 \%$ were delivered with low birth weight. Birth weight was unknown in $27 \%$. Majority were full term (37 to 41 weeks) (26\%), followed by moderately preterm (23\%) and very preterm (18 to 31 weeks) (Table 3 ). Approximately $27 \%$ had unknown birth weight.

Table 3. Distribution of CP patients as to perinatal history

\begin{tabular}{|c|c|c|}
\hline Characteristic & Frequency $(n=125)$ & Percentage \\
\hline \multicolumn{3}{|l|}{ Gestational age (in weeks) } \\
\hline Post term $\quad(>41)$ & 0 & 0.00 \\
\hline Full term & 32 & 25.60 \\
\hline Moderately preterm (32-36) & 29 & 23.20 \\
\hline Very preterm & 17 & 13.60 \\
\hline Extremely preterm (21-27) & 0 & 0.00 \\
\hline Unknown & 34 & 27.20 \\
\hline \multicolumn{3}{|l|}{ Birth weight (in $\mathrm{kg}$ ) } \\
\hline High $\quad(\geq 3.6)$ & 2 & 1.60 \\
\hline Normal & 43 & 34.40 \\
\hline$(1.3-2.2)$ & 35 & 28.00 \\
\hline Very low $\quad(1.0-1.2)$ & 11 & 8.80 \\
\hline Extremely low $(<1.0)$ & 0 & 0.00 \\
\hline Unknown & 34 & 27.20 \\
\hline \multicolumn{3}{|l|}{ Onset and cause } \\
\hline Congenital & 30 & 24.00 \\
\hline Perinatal (birth to 28 days) & 52 & 41.60 \\
\hline Postnatal (28 days to 5 years) & 43 & 34.40 \\
\hline
\end{tabular}

As to limbs affected, four-limb involvement was the most common distribution pattern (36\%), followed by diplegia (26\%) and unilateral arm and leg involvement at $16 \%$ for right-sided and $15 \%$ for left-sided. Six percent manifested with three-extremity involvement.

Regarding classification of cerebral palsy based on tone, the study showed hypertonicity/spasticity was the predominant type (50\%), followed by dystonia $(40 \%)$ and choreoathetosis in $10 \%$. None of the patients presented with hypotonia. For the level of sensorium, the participants generally had individualized response (39\%) and were oriented $(34 \%)$. This function could not be determined in the rest of the participants secondary to young age or inability to follow directions.

Only 35 participants (29\%) had cranial imaging to confirm the diagnosis of cerebral palsy. Of these patients, CT scan $(37 \%)$ was more frequently requested $(37 \%)$ than MRI (31\%) and cranial ultrasound (31\%).

Table 4 shows the accompanying conditions among the study participants. All participants presented with verbal communication and feeding problems. Speech was assessed as slow and somewhat difficult to understand by a new listener in $29 \%$ while $25 \%$ communicated verbally with severe limitations and used signs or gestures; $7 \%$ communicated in a generally age-appropriate way. For dysphagia, $47 \%$ were on mixed oral and tube feeding of varying proportions while $15 \%$ were exclusively tube-fed. Approximately $63 \%$ had comprehension difficulties 
described as severe difficulty in $26 \%$, mild difficulty in $23 \%$, while $14 \%$ did not understand language at all. The remaining $27 \%$ had no difficulty in comprehension. Seizure was noted in $58 \%$ of the participants. Concerns with behavior were present in $58 \%$ of the participants. Sensory impairments were also evident, with visual problems reported in 56\% and hearing deficits in 54\%. In addition, $20 \%$ had respiratory problems.

Table 4. Distribution of CP patients as to accompanying conditions

\begin{tabular}{lcc}
\hline \multicolumn{1}{c}{ Accompanying condition } & Frequency $(\mathbf{n}=\mathbf{1 2 5})$ & Percentage \\
\hline Seizure & 73 & 58.40 \\
Visual problems & 70 & 56.00 \\
Respiratory problems & 25 & 20.00 \\
Hearing deficits & 67 & 53.60 \\
Understanding language & 100 & 80.00 \\
Communication problems & 125 & 100.00 \\
Behavior problems & 72 & 57.60 \\
Swallowing problems & 125 & 100.00 \\
\hline
\end{tabular}

Medications for spasticity (58\%) and seizure (46\%) were the most frequently reported intervention (Table 5). Common surgical interventions were shunting for hydrocephalus (18\%) and lower extremity surgery (6\%). None of the participants underwent upper extremity or spine surgeries.

Table 5. Distribution of CP patients as to medications and surgical intervention

\begin{tabular}{lcc}
\hline \multicolumn{1}{c}{ Intervention } & Frequency $(\mathbf{n}=\mathbf{1 2 5})$ & Percentage \\
\hline Medication & 73 & \\
Spasticity & 57 & 58.40 \\
Anti-convulsant/seizure & 0 & 45.60 \\
Gastrointestinal & 23 & 0.00 \\
Pulmonary & 0 & 18.40 \\
ADHD*/behavioral & 37 & 0.00 \\
Botulinum toxin Injection & 0 & 29.60 \\
Others & & 0.00 \\
Surgery & 23 & 18.40 \\
Shunt & 0 & 0.00 \\
Upper extremity & 7 & 5.60 \\
Lower extremity & 0 & 0.00 \\
Spine & & \\
\hline
\end{tabular}

On utilization of assistive devices, wheelchair was the most commonly used mobility device (37\%), followed by walkers $(20 \%)$ and commercially-available custom strollers (19\%). Four percent used the local walker (andador) while 9\% who were ambulatory did not use an assistive device.

Seventy-one percent of the participants had access to a healthcare facility other than the Philippine General Hospital, most of which were secondary hospitals (39\%) and health centers (18\%) (Table 6). Only 10\% had access to primary hospitals. For rehabilitation services: approximately $73 \%$ had access to government facilities, $7 \%$ had access to private facilities, and $2 \%$ had school-based services (Table 6). Eighteen percent of the participants did not have access to rehabilitation facility.
Table 6. Distribution of $\mathrm{CP}$ patients as to access to healthcare and rehabilitation facility other than the Philippine General Hospital

\begin{tabular}{lcc}
\hline \multicolumn{1}{c}{ Facility } & Frequency $(\mathbf{n}=\mathbf{1 2 5})$ & Percentage \\
\hline Healthcare facility & 23 & \\
Health center & 13 & 18.40 \\
Primary hospital & 49 & 10.40 \\
Secondary hospital & 4 & 38.90 \\
Tertiary hospital & 0 & 3.20 \\
Rural health unit & 36 & 0.00 \\
No access & & 29.00 \\
Rehabilitation facility & 9 & \\
Private & 2 & 7.20 \\
School-based & 91 & 1.60 \\
Government & 23 & 72.80 \\
No access & & 18.40 \\
\hline
\end{tabular}

The different types of pediatric rehabilitation services provided to the participants were also explored. Physical therapy was the most frequent (64\%), followed by occupational therapy (29\%) and speech therapy (26\%). On the other hand, psychology services were less frequently availed of $(10 \%)$. Among participants aged $\geq 4$ years (school age), $29 \%$ were provided with special education (SPED).

This study also investigated the use of orthoses. Fortyfive percent of the participants used upper extremity orthoses, with majority having good compliance on the use of upper extremity orthoses (59\%). The most common upper extremity splint used was the resting hand splint $(26 \%)$; cock-up splint ranked second (12\%) and anti-deformity splint ranked third (7\%). Fifty-two percent used lower extremity orthoses, with compliance to use at $63 \%$. The most commonly prescribed splint was the posterior ankle splint $(43 \%)$, followed by a variety of hinged ankle foot orthoses at $9 \%$.

Family income plays a vital role in the patient's compliance with his/her prescribed rehabilitation management. In this study, majority have a gross monthly family income of P5,000-P10,000 (67\%), followed by < P5,000 (20\%), and P10,000-P20,000 (9\%).

Mobility was assessed in terms of Gross Motor Function Classification System (GMFCS) with a score of 1 as most functional and 5 as the least functional (Table 7). Majority of the patients had GMFCS score of 3 (29\%) which corresponds to: ability to maintain floor sitting with back support for ages 0 to 2 years, $\mathrm{W}$-sitting on the floor for ages 2 to 4 years, sitting on a regular chair with pelvic and trunk support for ages 4 to 6 years, limited ambulation with assistive/mobility device for ages 6 to 12 and indoor ambulation using a hand-held mobility device for ages 12 to 18 years. These were children with better mobility status: GMFCS 2 (25\%) and GMFCS 1 (15\%). In contrast, 15\% of the participants belonged to the most severe level (GMFCS 5). Functional Mobility Scale describes the mobility of participants aged 4 to 18 years. In this scale, a higher score corresponds to less need for assistive device during ambulation and vice versa. Majority of the participants had 
FMS score of 2 (55\%), followed by FMS score of 1 (uses a wheelchair, stroller, buggy) (43\%) (Table 7). Two percent had FMS score of 5 .

Table 7. Distribution of CP patients as to mobility

\begin{tabular}{ccc}
\hline Activity & Frequency & Percentage \\
\hline Gross Motor Function & $n=125$ & \\
Classification System (0 - 18 years) & 19 & 15.20 \\
1 & 31 & 24.80 \\
2 & 36 & 28.80 \\
3 & 20 & 16.00 \\
4 & 19 & 15.20 \\
5 & $n=56$ & \\
Functional Mobility Scale (4-18 years) & 24 & 42.86 \\
1 & 31 & 55.36 \\
2 & 0 & 0.00 \\
3 & 0 & 0.00 \\
4 & 1 & 1.79 \\
\hline
\end{tabular}

The Manual Ability Classification System (MACS) scores of the participants aged 4 to 18 years were mostly score of 2 (30\%) and score of 3 and 4 (both 23\%) (Table 8). A score of 2 corresponds with ability to handle most objects with somewhat reduced quality and/or speed. Best score for MACS is a score of 1 (handled objects easily and successfully) while a score of 5 indicates inability to handle objects and severely limited ability to perform even simple actions. For participants with age 4 years and below, the Peabody Developmental Motor Scales-2 (PDMS-2) was used. Majority of the participants were in the 'below average' (26\%), followed by 'average' (20\%), and both 'above average' and 'poor' (13\%) quotient scores. Seven percent of the participants had 'very poor' quotient score (Table 8). An 'average score' corresponds to performance of tasks within the normal range of age-matched peers.

Table 8. Distribution of CP patients as to hand function

\begin{tabular}{|c|c|c|}
\hline Manual Ability Classification System ( $4-18$ years) & $n=56$ & $\%$ \\
\hline 1 & 6 & 10.71 \\
\hline 2 & 17 & 30.35 \\
\hline 3 & 13 & 23.21 \\
\hline 4 & 13 & 23.21 \\
\hline 5 & 7 & 12.50 \\
\hline 6 & 0 & 0.00 \\
\hline Peabody Developmental & $n=69$ & \\
\hline \multicolumn{3}{|l|}{ Motor Scales $-2(0-4$ years $)$} \\
\hline $131-165$ (very superior) & 8 & 11.59 \\
\hline $121-130$ (superior) & 6 & 8.70 \\
\hline $111-120$ (above average) & 9 & 13.04 \\
\hline $90-110$ (average) & 14 & 20.29 \\
\hline $80-89$ (below average) & 18 & 26.09 \\
\hline $70-79$ & 9 & 13.04 \\
\hline (very poor) & 5 & 7.25 \\
\hline
\end{tabular}

Subgroup analysis was performed to evaluate the relationship of spasticity to mobility (GMFCS score) and hand function (MACS score and PDMS-2 score). Table 9 shows the relationship between lower extremity spasticity and GMFCS score. Majority of the participants exhibited grade 1 to $1+$ spasticity $(56 \%)$, most with GMFCS score of 3 (18\%) followed by score of 2 (16\%) and score of 1 at $14 \%$. Patients with grade 4 spasticity represented the minority (4\%); all had GMFCS score of 5 .

Table 9. Distribution of CP patients as to lower extremity spasticity and GMFCS score

\begin{tabular}{ccccc}
\hline \multirow{2}{*}{ GMFCS score } & \multicolumn{4}{c}{ Spasticity $(\mathbf{n = 1 2 5 )}$} \\
\cline { 2 - 5 } & $\begin{array}{c}\text { Grade 1 to 1+ } \\
(\mathbf{n}=\mathbf{7 0})\end{array}$ & $\begin{array}{c}\text { Grade 2 } \\
\mathbf{( n = 3 1 )}\end{array}$ & $\begin{array}{c}\text { Grade 3 } \\
(\mathbf{n}=\mathbf{1 9 )}\end{array}$ & $\begin{array}{c}\text { Grade 4 } \\
(\mathbf{n}=5)\end{array}$ \\
\hline I & $17(13.6 \%)$ & $2(1.6 \%)$ & $0(0)$ & $0(0)$ \\
II & $20(16.0 \%)$ & $11(8.8 \%)$ & $0(0)$ & $0(0)$ \\
III & $22(17.6 \%)$ & $8(6.4 \%)$ & $6(4.8 \%)$ & $0(0)$ \\
IV & $8(6.4 \%)$ & $4(3.2 \%)$ & $8(6.4 \%)$ & $0(0)$ \\
V & $3(2.4 \%)$ & $6(4.8 \%)$ & $5(4.0 \%)$ & $5(4.0 \%)$ \\
\hline
\end{tabular}

Table 10 presents the relationship between upper extremity spasticity of the upper extremities and hand function. Majority of the participants had grade 2 spasticity (50\%). Among these, $18 \%$ had a MACS score of 3 . Those with grade 3 spasticity either had MACS score of 4 or 5, in equal distribution (7\%). For patients with less spasticity (Grade 1 to $1+$ ), most showed MACS score of 2 (18\%).

Table 10. Distribution of CP patients as to upper extremity spasticity and MACS score

\begin{tabular}{ccccc}
\hline \multirow{2}{*}{ MACS score } & \multicolumn{4}{c}{ Spasticity $\left(\mathbf{n}=\mathbf{5 6} \mathbf{6}^{*}\right)$} \\
\cline { 2 - 5 } & $\begin{array}{c}\text { Grade 1 to 1+ } \\
\mathbf{n = 2 0}\end{array}$ & $\begin{array}{c}\text { Grade } 2 \\
\mathbf{n = 2 8}\end{array}$ & $\begin{array}{c}\text { Grade 3 } \\
\mathbf{n = 8}\end{array}$ & $\begin{array}{c}\text { Grade 4 } \\
\mathbf{n = 0}\end{array}$ \\
\hline I & $5(8.9 \%)$ & $1(1.8 \%)$ & $0(0)$ & $0(0)$ \\
II & $10(17.9 \%)$ & $7(12.5 \%)$ & $0(0)$ & $0(0)$ \\
III & $3(5.4 \%)$ & $10(17.9 \%)$ & $0(0)$ & $0(0)$ \\
IV & $2(3.6 \%)$ & $7(12.5 \%)$ & $4(7.1 \%)$ & $0(0)$ \\
V & $0(0)$ & $3(3.6 \%)$ & $4(7.1 \%)$ & $0(0)$ \\
VI & $0(0)$ & $0(0)$ & $0(0)$ & $0(0)$ \\
\hline
\end{tabular}

*Participants 4 years of age and above

For evaluation using the PDMS-2 score (Table 11), majority of the participants who exhibited grade 2 spasticity (49\%) belonged to the 'below average' group (16\%). For those with Grade 1 to 1+ spasticity, 33\% of the participants, most had'superior' to 'very superior' scores (13\%). In contrast, $4 \%$ of the participants had a spasticity grade of 4 and all had PDMS-2 score of 'poor' to 'very poor'.

Table 11. Distribution of $\mathrm{CP}$ patients as to upper extremity spasticity and PDMS-2 score

\begin{tabular}{ccccc}
\hline \multirow{2}{*}{ PDMS-2 score } & \multicolumn{4}{c}{ Spasticity (n=69*) } \\
\cline { 2 - 5 } & $\begin{array}{c}\text { Grade 1 to 1+ } \\
\mathbf{n = 2 3}\end{array}$ & $\begin{array}{c}\text { Grade 2 } \\
\mathbf{n = 3 4}\end{array}$ & $\begin{array}{c}\text { Grade 3 } \\
\mathbf{n = 9}\end{array}$ & $\begin{array}{c}\text { Grade 4 } \\
\mathbf{n = 3}\end{array}$ \\
\hline $\begin{array}{c}\text { Superior to Very superior } \\
(121-165)\end{array}$ & $9(13.05)$ & $5(7.2 \%)$ & $0(0)$ & $0(0)$ \\
$\begin{array}{c}\text { Above average } \\
(111-120)\end{array}$ & $4(5.8 \%)$ & $5(7.2 \%)$ & $0(0)$ & $0(0)$ \\
$\begin{array}{c}\text { Average (90-110) } \\
\text { Below average (80-89) } \\
\text { Poor to Very poor } \\
(69-79)\end{array}$ & $3(4.3 \%)$ & $9(13.0 \%)$ & $2(2.9 \%)$ & $0(0)$ \\
\hline
\end{tabular}

*Participants less than 4 years old 


\section{Discussion}

This is the first study consolidating data on cerebral palsy among pediatric patients conducted at a tertiary government hospital, with the goal of creating a framework for a hospital-wide cerebral palsy registry to be spearheaded by the Department of Rehabilitation Medicine.

Our study included a total of 125 participants recruited from September 1, 2014 to December 31, 2015, corresponding to approximately 8 patients seen per month. This was calculated from 910 new pediatric patients seen during the 16-month recruitment period (13\%). In a comprehensive status report of PGH Pediatric Rehabilitation Service covering the period 2007-2009, cerebral palsy is the leading diagnosis of new patients referred to the service on outpatient basis, totaling 329 out of $1,173(28 \%) .^{5}$

As to content of the data collection form used in this study, there was a notable similarity with a 2001 Danish registry which included the following: cerebral palsy subtype, severity of motor handicap described in terms of ability to walk, orthopedic operations, and accompanying nervous system diseases (eg, mental retardation, epilepsy and problems with hearing, vision or, speech). ${ }^{8}$ The Danish registry also contained demographic data on the child and mother and information on maternal disease, pregnancy complications, gestational age, birth weight, mode of delivery, congenital malformations, results of neuroimaging, and the timing of brain insult. ${ }^{8}$ APGAR score and congenital malformations were included in the Danish registry but not in this study.

Data from our study suggest that the population of $\mathrm{CP}$ patients at the PGH Rehabilitation Medicine OPD clinic had a comparable trend in selected variables with other countries that have existing and/or established registries. There was a $58 \%$ male predominance in our study, similar to a Hong Kong registry published in 2006, with male predominance $(67 \%)^{12}$. The 2013 Australian CP Register Report also reported male predominance $57.3 \%$ in comparison to $51 \%$ of births in Australia. ${ }^{27}$

Recent efforts to survey the prevalence of $\mathrm{CP}$ had been made in other developing countries. In China, a study reported relatively low prevalence of 1.6 per 1000 children $<7$ years was reported in $1997 .{ }^{28}$ In the same study, birth weight-specific prevalence was reported at 67.3 per 1000 in those who weighed 1500 to 1749 grams and 0.8 per 1000 births in infants weighing 3750 to 3999 grams.

A 2013 Pakistan study showed that more than $90 \%$ of mothers were homemakers and $50 \%$ had completed primary-level education. ${ }^{13}$ In our study, approximately $70 \%$ of primary caregivers were housewives/husbands and completed high school (42\%), that may imply that the Filipino primary caregivers have higher level of educational status than the caregivers in Pakistan. Mothers were the most frequent primary caregivers $(45 \%)$ in our study similar to the above-mentioned study.
A Japanese study in 2009 cited the major causes and risk factors for $\mathrm{CP}$ in term infants: brain dysplasia $(17 \%)$, vascular disorders (15\%), hypoxic ischemic encephalopathy $(14 \%)$, periventricular leukomalacia $(8 \%)$, and intrauterine growth retardation (19\%). ${ }^{10}$ A detailed list of causes or risk factors was difficult to generate in our study because most of the patients did not have the necessary neuroimaging studies to correlate with, with only $29 \%$ who presented with diagnostic cranial imaging. In addition, information on the birth and maternal history was scarce or unknown in patients whose caregivers interviewed were not the parents.

In Japan, the proportion of $\mathrm{CP}$ patients with low birth weight and gestational age had been increasing. ${ }^{9}$ In our study, there were more patients with normal birth weight $(34 \%)$ than low birth weight infants $(28 \%)$. In terms of gestational age, moderately preterm infants comprised the majority at $23 \%$, concurring with the Japanese report. This may be attributed to better availability of resuscitative and supportive equipment in the local setting in the recent years as is seen in developed and industrialized countries that augment the survival of these low birth weight and pre-term infants. Specifically, the improvement in survival of preterm babies may have been contributory to a rise in the case of $\mathrm{CP} .{ }^{8}$

A higher rate of quadriplegic and dyskinetic patients was seen in special needs schools in Hong Kong, ${ }^{12}$ in contrast to our results that showed quadriplegic (36\%) and hypertonic $(50 \%)$ as the predominant types. In Japan, spastic diplegia $(43 \%)$ and tetraplegia $(28 \%)$ represented the majority followed by hemiplegia $(18 \%)$ and dyskinetic type $(6 \%) .{ }^{11}$ Spastic type is the predominant motor type in Australia with bilateral spasticity manifested as diplegia, triplegia, and quadriplegia comprised approximately $61 \%$ and unilateral spasticity (hemiplegia or monoplegia) composed $39 \%$ of the total population of CP patients. ${ }^{27}$

In terms of mobility, a study in Japan by Suzuki et al reported that $44 \%$ of the participants walked alone at six years and $5 \%$ walked with a crutch. ${ }^{11}$ In contrast, majority of our patients walked with a hand-held mobility device (GMFCS score of 3) (29\%) or uses a walking frame without help from another person (GMFCS score of 2) (55\%); $4 \%$ were independent ambulators without any walking aide. In this study, the ambulatory participants who used walkers composed only $20 \%$ of the total number of participants. Majority of the non-ambulatory participants used either a wheelchair (37\%) or custom strollers (19\%).

In a local study by Socrates et al in 2000, it was reported that children with $\mathrm{CP}$ had poor nutritional status, significantly lower weight for height and smaller height and weight for age as well. ${ }^{29}$ These nutritional issues may have been caused by feeding difficulties. Our study suggested that CP patients presented with slow oral feeding and needed mixed tube-oral feeding. Patients with $\mathrm{CP}$ are at a high risk for aspiration and that gastrostomy tube feeding put these patients at a potential risk for overfeeding. ${ }^{30}$ 
Yam et al reported that patients with CP in Hong Kong attended special needs or mainstream schools and received school-based educational assistance and supportive therapy in the latter. ${ }^{12}$ In the same study, approximately $38 \%$ of children with CP attended mainstream school and $40 \%$ attended a mainstream school. Among those in special needs schools, 96\% attended either a school for the physically handicapped or attended school in an institution for the severely mentally-challenged. ${ }^{12}$ In contrast, our study revealed that only 16 out of 56 (29\%) aged four years and above went to special education (SPED) school and approximately only $10 \%$ underwent rehabilitation in schoolbased facilities. Majority of these patients had gross monthly family income between $<\mathrm{P} 5,000$ to $\mathrm{P} 10,000$ and this may have been one of the contributing factors to the low percentage in SPED enrollment. The Department of Rehabilitation Medicine SPED pre-school showed that among the students who were enrolled in 2014, approximately $18 \%$ were children with $\mathrm{CP}$. In contrast in Hong Kong, $26 \%$ of children with cerebral palsy received educational support, while $61 \%$ received out-patient therapy support and $12 \%$ had both services. ${ }^{12}$ In comparison, most of our patients had physical therapy $(69 \%)$ and occupational therapy (29\%). Speech therapy $(27 \%)$ and rehabilitation psychology $(10 \%)$ were less frequently given in our study. This may be due, in part, to the limited number of occupational therapists and speech therapists especially in remote provincial areas and/or limited financial resources for multiple comprehensive therapies.

The relationship of spasticity with function has been published in numerous literature. Gorter et al reported that spasticity is marginally related to gross motor function development in infants with $\mathrm{CP} .{ }^{31}$ Current studies in this population have shown a modest, negative association between spasticity and function in children aged three years and older. ${ }^{32-34}$ Another study by Katusic and Alimovic, reported that there is moderate correlation between spasticity and gross motor skills. ${ }^{35}$ In all the aforementioned studies pertaining to spasticity and gross motor function, it is stated however that spasticity is only one factor among many others that can interfere with gross motor function. There is paucity of literature on association of spasticity and hand function. In our study, poorer hand function was evident in patients with increasing spasticity.

\section{Conclusion and Recommendations}

It is recommended that a hospital-wide cerebral palsy registry be initiated at the Philippine General Hospital. Using the findings of this study, the characteristics of this study population can be closely monitored, as CP remains to be the most common childhood disability. Cerebral palsy is one of the top diagnoses of pediatric patients referred to our service for multidisciplinary and holistic care. The causes of $\mathrm{CP}$ are multifactorial and their impact on function is complex, therefore change in $\mathrm{CP}$ trends should be correlated with alterations in maternal, perinatal, and neonatal risk factors, health services, and socioeconomic levels. Data on impairment, disability level, and comorbidities of these children are indispensable for optimal management planning, since early intervention and good standard of care are expected to reduce the burden on the family and society to improve the opportunities for these children.

The limitations of our study were: 1) poor reliability of the information provided by the informant if other than the parents, 2) cognitive deficits were not explored, and 3) inclusion was limited to out-patients, children $<19$ years old. The Philippine General Hospital is a tertiary center providing subsidized care. Patients included in the study may have been more medically involved and neurodevelopmentally impaired with less financial capacity for comprehensive rehabilitation interventions. In comparison, patients belonging to higher socioeconomic class may avail of the most ideal interventions.

Continuing and/or future studies are recommended with inclusion of: 1) the patients' mother to improve data collection (egt, provision for re-interview if the mother was not available during the initial survey), 2) data on detailed pre-natal history, 3) data on profile of fathers, 4) additional tests to assess mental retardation and cognitive deficits to determine if communication difficulties are secondary to cognitive or organic etiology, 5) in-patients from Rehabilitation Medicine Ward and other wards in PGH (eg, Orthopedics, Pediatrics), 6)adults with $\mathrm{CP}$, and 7) detailed visual and hearing evaluation. This profile study may be used as a template for a registry to be spearheaded by the Department of Rehabilitation Medicine for a hospital-wide database. Moreover, community or population-based studies can be conducted in the future. Other specialties (eg, Ophthalmology, Otorhinolaryngology, Pediatric Neurology) will need to be involved in future studies as CP patients have multiple impairments and needs. Collaboration with the hospital administration is also warranted for logistic and technical support and sustainability.

Rehabilitation professionals, educators, and policy makers may acquire helpful information from future registries to keep abreast with existing and anticipated management of children with cerebral palsy for their medical, educational, and social service needs. Highly specialized personnel with adequate time and manpower are also necessary, as well as robust funding support to maintain and upgrade a registry.

\footnotetext{
Acknowledgment

The authors would like to acknowledge the Northwestern University in Chicago, USA for granting permission to use their $\mathrm{CP}$ Research Registry.
} 


\section{Statement of Authorship}

All authors have approved the final version submitted.

\section{Author Disclosure \\ All authors declared no conflict of interest.}

\section{Funding Source}

This paper was partially funded by the Philippine General Hospital and the authors.

\section{References}

1. Rosenbaum P, Paneth N, Leviton A, et al. A report: the definition and classification of cerebral palsy. Dev Med Child Neurol Suppl. 2007; 109:8-14.

2. Centers for Disease Control and Prevention Data \& Statistics for Cerebral Palsy [Online]. 2013 [cited 2013 Aug]. Available from http://www.cdc.gov/ncbddd/cp/data.html.

3. Hurley DS, Sukal-Moulton T, Msall M, Gaebler-Spira D, Krosschell KJ, Dewald JP. The cerebral palsy research registry: development and progress toward national collaboration in the United States. J Child Neurol. 2011; 26(12):1534-41.

4. Cans C, Surman G, McManus V, Coghlan D, Hensey O, Johnson A. Cerebral palsy registries. Semin Pediatr Neurol. 2004; 11(1):18-23.

5. Ang-Muñoz C, Lim-Dungca M, De Leon K, La Rosa M, Bigtas S. Pediatric rehabilitation service: status report (2007-2009). Department of Rehabilitation Medicine, College of Medicine and Philippine General Hospital, UP Manila. (Data on file).

6. Ang C, Agsaoay E, Carlos L, et al. Pediatric rehabilitation program: status report (1996-1999). Department of Rehabilitation Medicine, College of Medicine and Philippine General Hospital, UP Manila. (Data on file).

7. Philippine Cerebral Palsy Incorporated About Cerebral Palsy [Online]. 2011 [cited 2013 Aug]. Available from http://philippinecerebral palsy.org/about_cerebral.

8. Uldall P, Michelsen SI, Topp M, Madsen M. The Danish Cerebral Palsy Registry: A registry on a specific impairment. Dan Med Bull. 2001; 48(3):161-3.

9. Suzuki J, Miyajima T, Fujii T. Epidemiological study of cerebral palsy in Shiga prefecture, Japan during 1977-2000. Part 1: incidence pattern of cerebral palsy in Shiga prefecture with reference to birth weight and gestational age. No To Hattatsu. 2009; 41(4):279-83.

10. Suzuki J, Miyajima T, Fujii T. Epidemiological study of cerebral palsy in Shiga prefecture, Japan during 1977-2000. Part 2: etiologies and risk factors of cerebral palsy in Shiga prefecture. No To Hattatsu. 2009; 41(4):284-8.

11. Suzuki J, Miyajima T, Fujii T. Epidemiological study of cerebral palsy in Shiga prefecture, Japan during 1977-2000. Part 3: clinical features of cerebral palsy at six years of age. No To Hattatsu. 2009; 41(4):289-93.

12. Yam WK, Chan HS, Tsui KW, et al. Prevalence study of cerebral palsy in Hong Kong children. Hong Kong Med J. 2006; 12(3):180-4.

13. Ibrahim SH, Bhutta ZA. Prevalence of early childhood disability in a rural district of Sind, Pakistan. Dev Med Child Neurol. 2013; 55(4):357-63.

14. Persons with disabilities: status in the Philippines [Online]. 2014 [cited 2016 Mar]. Available from http://web.nlp.gov.ph/nlp/sites/default/ files/20Mar2014/Persons\%20with\%20Disabilities\%20by\%20Edgardo\%20 garcia.pdf.

15. Philippine General Hospital Rehabilitation Medicine Out-Patient Department census. 2012. (Data on file)
16. Herrin JA, Reyes A. A five-year review of referrals to the developmental pediatrics section of a major tertiary hospital. Acta Med Philipp. 2009; 43:(3)12-7.

17. De Leon VC, Tabla DJ, Quintos F. Cerebral palsy among Filipino children. Philipp J Pediatr. 1964.

18. Frisch D, Msall ME. Health, functioning, and participation of adolescents and adults with cerebral palsy: a review of outcomes research. Dev Disabil Res Rev. 2013; 18(1):84-94.

19. World CP Register Congress Survey Report [Online]. 2009 [cited 2013 Sep]. Available from https://research.cerebralpalsy.org.au/wpcontent/uploads/sites/3/2014/11/Report-of-the-international-survey-ofcerebral-palsy-registers-and-surveillance-systems-2009.pdf.

20. World Health Organization (WHO) International Classification of Function, Disability, and Health (ICF) [Online]. 2001 [cited 2013 Aug]. Available from http://www.who.int./classification/icf/en/.

21. Palisano RJ, Rosenbaum P, Bartlett D, Livingston MH. Content validity of the expanded and revised Gross Motor Function Classification System. Dev Med Child Neurol. 2008; 50(10):744-50.

22. Eliasson AC, Krumlinde-Sundholm L, Rosblad B, et al. The Manual Ability Classification System (MACS) for children with cerebral palsy: scale development and evidence of validity and reliability. Dev Med Child Neurol. 2006; 48(7):549-54.

23. Harvey A, Baker R, Morris ME, Hough J, Hughes M, Graham HK. Does parent report measure performance? a study of the construct validity of the Functional Mobility Scale. Dev Med Child Neurol. 2010; 52(2):181-5.

24. van Hartingsveldt MJ, Cup EH, Oostendorp RA. Reliability and validity of the fine motor scale of the Peabody Developmental Motor Scales-2. OccupTher Int. 2005; 12(1):1-13.

25. Mockford M, Caulton JM. Systematic review of progressive strength training in children and adolescents with cerebral palsy who are ambulatory. Pediatr Phys Ther. 2008; 20(4):318-33.

26. Michelsen SI, Flachs EM, Damgaard MT, et al. European study of frequency of participation of adolescents with and without cerebral palsy. Eur J Paediatr Neurol. 2014; 18(3):282-94.

27. Australian Cerebral Palsy Register Report 2013 [Online]. 2013 [cited 2013 Sep]. Available from https://www.cerebralpalsy.org.au/wpcontent/uploads/2013/04/ACPR-Report_Web_2013.pdf.

28. Liu JM, Li S, Lin Q, Li Z. Prevalence of cerebral palsy in China. Int J Epidemiol. 1999; 28(5):949-54.

29. Socrates C, Grantham-Mcgregor SM, Harknett SG, Seal AJ. Poor nutrition is a serious problem in children with cerebral palsy in Palawan, the Philippines. Int J Rehabil Res. 2000; 23(3):177-84.

30. Sullivan PB, Alder N, Bachlet AM, et al. Gastrostomy feeding in cerebral palsy: too much of a good thing?. Dev Med Child Neurol. 2006; 48(11):877-82.

31. Gorter JW, Verschuren O, van Riel L, Ketelaar M. The relationship between spasticity in young children (18 months of age) with cerebral palsy and their gross motor function development. BMC Musculoskelet Disord. 2009;10:108.

32. Ostensjo S, Carlberg EB, Vollestad NK. Everyday functioning in young children with cerebral palsy: functional skills, caregiver assistance, and modifications of the environment. Dev Med Child Neurol. 2003; 45(9):603-12.

33. Abel MF, Damiano DL, Blanco JS, et al. Relationships among musculoskeletal impairments and functional health status in ambulatory cerebral palsy. J Pediatr Orthop. 2003;23(4):535-41.

34. Ross SA, Engsberg JR. Relationships between spasticity,strength, gait, and the GMFM-66 in persons with spastic diplegia cerebral palsy. Arch Phys Med Rehabil. 2007;88(9):1114-20.

35. Katusic A, Alimovic S. The relationship between spasticity and gross motor capability in nonambulatory children with spastic cerebral palsy. Int J Rehabil Res. 2013; 36(3):205-10. 